\title{
IDENTIFICATION MICROPLASTIC WASTE IN SEAWATER AND THE DIGESTIVE ORGANS OF SENANGIN FISH (E. tetradactylum) AT DUMAI CITY SEA WATERS
}

\author{
Awis Mirad ${ }^{1 *}$, Dessy Yoswaty ${ }^{2}$, Thamrin ${ }^{2}$ \\ ${ }^{1}$ Student of the Faculty of Fisheries and Marine Universitas Riau, Pekanbaru \\ ${ }^{2}$ Lecturer at the Faculty of Fisheries and Marine Universitas Riau, Pekanbaru \\ *awismirad2727@gmail.com
}

\begin{abstract}
The research was conducted on November 2019 with sampling at the sea waters of Dumai, Riau province. Further, analysis samples in the Marine Chemistry's Laboratory on Marine Sciences Department in Fisheries and Marine Faculty University of Riau. Method used method of survey. The form of data collection is the primary data obtained from survey activities and observation data from samples that have been analyzed in the laboratory. The results of the study showed that the type of microplastic found in sea water and Senangin ( $E$. Tetradactylum) is a type of microplastic fiber, fragments, and film. Microplastic pellet type was not finding in this research. The abundance of microplastics in seawater samples ranges from 333,3333-456,6667 particles $/ \mathrm{m}^{3}$, while the abundance of microplastics in Senangin fish (E. tetradactylum) is 966,6667-1933,3333 particles/Ind.
\end{abstract}

Keywords: Dumai, E. tetradactylum, Mikroplastic.

\section{PENDAHULUAN}

Kota Dumai merupakan salah satu kawasan pesisir paling strategis dimana posisinya berada sebagai gerbang bagian utara dari Provinsi Riau yang berhubungan langsung dengan perairan internasional Selat Melaka. Kota Dumai merupakan kota dengan penduduk terpadat Kedua di Provinsi Riau dan merupakan kota industri terbesar yang terletak di

kawasan pesisir utara Provinsi Riau. Seiring meningkatnya jumlah penduduk di Kota Dumai, dan banyaknya aktivitas masyarakat (antropogenik). Hal ini diduga menghasilkan bahan pencemar (limbah industri dan domestik), termasuk limbah organik dan anorganik. Salah satu tekanan yang dapat mempengaruhi kerusakan ekosistem pesisir adalah pencemaran sampah laut.
Salah satu dari sekian banyaknya sampah laut yang menjadi perhatian dunia adalah limbah plastik. Meningkatnya ketergantungan manusia terhadap penggunaan plastik dalam berbagai aplikasi tanpa disadari menimbulkan dampak jangka panjang. Sampah plastik yang dihasilkan oleh manusia akhirnya akan kembali dibuang ke lingkungan (Victoria, 2017).

Masalah timbul saat plastik telah berakhir sebagai limbah. Sifatnya yang persisten membuat plastik tidak mudah hilang secara langsung di lingkungan. Kebanyakan plastik akan berakhir di laut dan menjadi sumber pencemar utama dengan jumlah sebesar 60-80\% dari jumlah limbah di laut (Moore, 2008).

Mikroplastik merupakan jenis sampah plastik yang berukuran 0.3-5 mm. Batas bawah ukuran partikel yang termasuk 
ke dalam kelompok mikroplastik belum didefinisikan secara pasti namun kebanyakan penelitian mengambil objek minimal $300 \mu \mathrm{m}$. Mikroplastik terbagi menjadi 2 kategori ukuran yaitu (1-5 mm) dan kecil (<1 mm) (Tankovic et al., 2015).

Mikroplastik dapat terakumulasi dalam jumlah yang tinggi pada air laut dan sedimen (Hidalgo-Ruz et al., 2012). Ukuran mikroplastik yang sangat kecil dan jumlahnya yang banyak di lautan membuat sifatnya ubiquitous dan bioavailability bagi organisme akuatik tinggi. Akibatnya mikroplastik dapat termakan oleh biota laut (Li et al., 2016).

Hal yang menjadi kekhawatiran adalah karena ukurannya yang sangat kecil, Mikroplastik memungkinkan untuk masuk dalam tubuh biota laut seperti ikan dan bivalvia, akibatnya polutan ini dapat masuk dalam sistem rantai makanan (aquatic food chain). Apabila mikroplastik masuk ke dalam tubuh organisme laut (ikan, kerang, crustacean) dan sudah menyerap berbagai polutan, maka akan mengganggu sistem pencernaan, peredaran darah dan organ lainnya pada organisme laut tersebut. Dengan demikian keberadaan polutan plastik ini dalam biota akuatik yang dikonsumsi manusia dapat memberikan risiko keamanan pangan yang perlu dikaji lebih jauh.

Berdasarkan latar belakang tersebut penulis tertarik melakukan penelitian tentang identifikasi limbah mikroplastik pada air laut dan organ pencernaan ikan senangin (E. tetradactylum) di perairan laut Kota Dumai.

\section{METODE PENELITIAN Waktu dan Tempat}

Penelitian ini telah di laksanankan pada bulan November 2019 dengan pengambilan sampel di perairan laut Kota Dumai Provinsi Riau. Selanjutnya analisis sampel di Laboratorium Kimia Laut Jurusan Ilmu Kelautan Fakultas Perikanan dan Kelautan Universitas Riau.

\section{Metode Penelitian}

Penelitian ini menggunakan metode survei. Bentuk pengumpulan data yaitu data primer berupa data yang didapat dari kegiatan survei dan data pengamatan dari sampel yang telah dianalisis di laboratorium.

\section{Prosedur Penelitian \\ Penentuan Lokasi dan Titik Sampling}

Lokasi penelitian ini ditentukan dengan cara purposive sampling atau dengan memperhatikan pertimbangan kondisi dan keadaan daerah penelitian. Lokasi Pengambilan sampel dibagi atas 3 titik stasiun. Masing-masing stasiun terdiri dari atas daerah yang merupakan kawasan perairan laut yang berdekatan dengan muara sungai masjid (stasiun 1), pantai wisata purnama (stasiun 2), dan kawasan perairan yang dekat dengan tempat pelelangan ikan (TPI) (stasiun 3). Lokasi ini dipilih karena dekat dengan aktivitas manusia. Sampel biota (ikan senangin) diperoleh dari hasil tangkapan nelayan setempat.

\section{Pengambilan dan Penanganan Sampel Air laut}

Sampel air laut dikumpulkan menggunakan botol polyethylene 250 mililiter ( $\mathrm{ml}$ ) dipasangkan pada mulut bawah plankton net. Jaring penyusun dari plankton net menggunakan ukuran 0,4 milimeter. Sampel air laut disetiap stasiun diambil sebanyak 3 kali pengulangan (3 sampel/stasiun). Sampel air laut yang di saring ialah bagian air permukaan dengan menggunakan ember bervolume 10 liter dengan 10 kali pengulangan penyaringan (100 liter), dimana pengambilan sampel air laut dilakukan secara random 100 meter vertikal kearah laut. Lalu sampel air laut diberi label dan disimpan dalam cool box untuk dianalisis lebih lanjut di Laboratorium. 


\section{Pengambilan dan Penanganan Sampel Ikan}

Sampel biologi didapat dari hasil tangkapan nelayan yang menjaring ikan disekitaran perairan laut Kota Dumai dan sampel biologis yang diambil adalah sampel ikan Senangin (E. tetradactylum), seluruh sampel disimpan pada plastik sampel dan diberi larutan Formalin 4\% agar sampel tidak mengalami pembusukan selama perjalanan dan disimpan di dalam cool box untuk dianalisis lebih lanjut di laboratorium Kimia Laut Jurusan Ilmu Kelautan Fakultas Perikanan dan Kelautan Universitas Riau.

\section{Pengukuran Parameter Kualitas Perairan}

Pengukuran parameter kualitas perairan meliputi, suhu, salinitas, $\mathrm{pH}$, kecerahan, kecepatan arus. Parameter ini diukur saat pasang untuk pengambilan sampel dengan tiga kali pengulangan pada masing-masing titik sampling. Tujuannya adalah untuk menggambarkan kondisi perairan pada saat penelitian dilaksanakan.

\section{Suhu}

Pengukuran suhu perairan menggunakan Thermometer. Thermometer diikat pada bagian pangkal menggunakan tali plastik, kemudian dicelupkan kedalam perairan selama beberapa menit sampai angka yang menunjukkan suhu tersebut stabil. Dicatat nilai suhu pada Thermometer tersebut.

\section{Salinitas}

Pengukuran salinitas dengan menggunakan Handrefractometer yang terlebih dahulu dikalibrasi dengan aquades hingga nilainya nol, kemudian diambil sampel air laut dengan menggunakan pipet tetes dan diteteskan pada lensa yang terdapat pada Handrefractometer, setelah itu dilihat pada skala yang ada pada Handrefractometer. Dicatat nilai yang dihasilkan Handrefractometer.

\section{Kecepatan Arus}

Kecepatan arus diukur dengan menggunakan Current drouge. Alat ini dilepaskan ke permukaan perairan dan bersamaan dengan Stopwatch diaktifkan. Kecepatan arus dapat diketahui dengan rumus sebagai berikut:

$\mathrm{v}=\mathrm{s} / \mathrm{t}$

Keterangan:

$\mathrm{v}=$ Kecepatan arus (m/det)

$\mathrm{s} \quad=$ Jarak yang ditempuh dari titik awal hingga jarak tertentu (m)

$\mathrm{t}=$ Waktu yang diperlukan untuk mencapai titik tertentu (det)

\section{Analisis sampel Air laut}

Persiapan sampel dilakukan dengan menyiapkan sampel, pembuatan longsheet pengerjaan serta mempersiapkan bahan dan alat yang dibutuhkan dalam proses selanjutnya. Pemisahan sampel dilakukan penyaringan menggunakan sieve yang lebih kecil dari $300 \mu \mathrm{m}$ untuk memisahkan sampah meso dengan mikro. Air saringan, disaring kembali menggunakan kertas saring whattman berukuran $45 \mu \mathrm{m}$ dengan vacuum filtration (Hastuti, 2014) dan ditunggu hingga kering. Lalu sampel yang sudah disaring diamati secara visual di bawah Mikroskop Olympus CX 23 dan mikroplastik yang ditemukan dihitung berdasarkan jenis yang ditemukan.

Kelimpahan mikroplastik dapat dihitung berdasarkan jumlah partikel yang ditemukan dibagi air yang tersaring (NOAA, 2013).

Keterangan:

$$
\mathrm{C}=\mathrm{n} / \mathrm{V}
$$

$\mathrm{C}=$ Kelimpahan (Partikel $\left./ \mathrm{m}^{3}\right)$

$\mathrm{n}=$ Jumlah Partikel yang ditemukan

$\mathrm{V}=$ Volume air yang tersaring

\section{Analisis Sampel Ikan}

Identifikasi mikroplastik berdasarkan metode Rochman et al., (2015) dilakukan melalui beberapa tahapan yaitu (a) 
pembedahan, (b) pemisahan seluruh saluran pencernaan, (c) perendaman organ pencernaan dengan larutan $\mathrm{KOH} 10 \%$ dengan perbandingan $1: 3$, (d) inkubasi selama 2 minggu, (e) pengamatan mikroplastik menggunakan sedgewick Rafter Counting Cell dibawah Mikroskop Olympus CX 23 dengan mengambil sebanyak $1 \%$ dari jumlah total larutan. Kemudian sampel mikroplastik digolongkan dalam beberapa jenis yakni fiber, film, fragmen dan pelet.

\section{HASIL DAN PEMBAHASAN Kondisi Umum}

Kota Dumai merupakan salah satu kota hasil pemekaran dari Kabupaten Bengkalis, yang terbentuk pada tanggal 27 April 1999 berdasarkan Undang-Undang Nomor 16 Tahun 1999, yang ditetapkan dalam lembaran Negara nomor 50 Tahun 1999. Secara geografis Kota Dumai terletak pada posisi antara $1^{\circ} 23^{\prime} 00^{\prime \prime}-1^{\circ} 24$ '23" Lintang Utara dan $101^{\circ} 233^{\prime} 37^{\prime \prime}-101^{\circ} 28^{\prime} 13^{\prime \prime}$ Bujur Timur. Kota Dumai mempunyai luas 1,727.38 dan merupakan kota kedua terbesar di Indonesia Setelah Monokwari.

Kota Dumai sebagian terdiri dari dataran rendah di bagian Utara dan sebagian dataran tinggi di sebelah Selatan. Pada umumnya struktur tanah terdiri dari tanah podsolik merah kuning dari batuan endapan, aluvial, dan tanah organosol dan glei humus dalam bentuk rawa-rawa atau tanah basah. Di wilayah Kota Dumai terdapat 53 buah sungai yang dapat di lalui oleh kapal pompong, sampan, dan perahu sampai jauh ke daerah hulu sungai. Sungai Buluala, Sungai Senepis, dan Sungai Mesjid merupakan tiga sungai yang terpanjang dan mengalir langsung keperairan laut selat rupat (Badan Pusat Statistik Kota Dumai, 2019).

Dumai memiliki topografi yang relatif datar dengan ketinggian 1.3-6.3 m dari permukaan laut dan kemiringan 0-3\% sehingga sangat potensial dikembangkan sebagai pelabuhan utama di Pulau
Sumatera. Sebagai pintu gerbang pelayaran internasional, Dumai mampu berkembang menjadi pusat pelayanan jasa dan perdagangan. Pelabuhan Dumai mampu melayani aktifitas ekspor-impor barang dan penumpang domestik maupun manca negara. Selat Rupat berfungsi sebagai pintu gerbang pantai Timur Pulau Sumatera dengan jalur pelayaran Dumai - Batam, Dumai - Penang Malaysia (Badan Pusat Statistik Kota Dumai, 2019).

Secara geografis, Kota Dumai berdekatan langsung dengan Negara Malaysia. Aksesibilitas pelayaran yang tinggi dari dan keluar wilayah Indonesia membutuhkan pengamanan pelayaran yang ketat, karena wilayah ini berbatasan langsung dengan negara tetangga Malaysia (Badan Pusat Statistik Kota Dumai, 2019).

Berdasarkan observasi di lokasi penelitian, pengambilan sampel air laut dilakukan pada tiga stasiun dan pengambilan sampel ikan dengan cara menjelajah sebagian besar perairan laut Kota Dumai dengan bantuan nelayan setempat. Secara umum lokasi dari masingmasing stasiun dapat digambarkan sebagai berikut:
1. Stasiun $1\left(1^{\circ} 43^{\prime} 13^{\prime \prime} \mathrm{LU} ; 101^{\circ} 23^{\prime} 19^{\prime \prime}\right.$ BT)

Stasiun 1 merupakan wilayah yang dekat dengan muara sungai masjid Kelurahan Purnama Kota Dumai, wilayah ini merupakan daerah muara yang dekat dengan perindustrian, pemukiman warga, jalur keluar masuknya kapal nelayan dan juga tempat renovasi kapal kecil milik nelayan setempat.

\section{Stasiun $2\left(1^{\circ} 42^{\prime} 16^{\prime \prime}\right.$ LU $101^{\circ} 23^{\prime} 7^{\prime \prime}$ BT)}

Stasiun 2 merupakan wilayah pantai wisata yaitu pantai purnama, pantai ini merupakan salah satu pantai wisata yang memiliki jumlah pengunjung paling banyak setiap harinya terutama pada saat libur akhir pekan. Aktivitas seperti peredangn dan pemukiman juga terjadi didaerah ini. 


\section{Stasiun $3\left(1^{\circ} 41^{\prime} 17^{\prime \prime}\right.$ LU $101^{\circ} 26^{\prime} 18^{\prime \prime}$ BT)}

Stasiun 3 merupakan wilayah perairan yang dekat dengan TPI. Stasiun 3 merupakan stasiun dengan aktivitas antopogenik yang ramai dan merupakan kawasan keluar masukknya kapal-kapal nelayan dan berbedakatan dengan pusat Kota Dumai yang merupakan wilayah padat penduduk yang kemungkinan besar banyak membawa limbah-limbah padat seperti limbah organik maupun limbah plastik.

\section{Parameter Kualitas Perairan}

Parameter kulitas perairan Laut Kota Dumai dilakuakan dengan dengan 3 kali pengulangan, hasil yang pengukuran kulaitas perairan laut Kota Dumai kualitas perairan laut Kota Dumai dapat dilihat pada Tabel 1.

Tabel 1. Parameter Kualitas Perairan

\begin{tabular}{cccc}
\hline Stasiun & Suhu $\left({ }^{\circ} \mathrm{C}\right)$ & Salinitas (\%o) & Kecepatan Arus (m/det) \\
\hline Stasiun 1 & 30,3 & 25 & 0,14 \\
Stasiun 2 & 30,3 & 25 & 0,13 \\
Stasiun 3 & 31,3 & 25 & 0,14 \\
\hline
\end{tabular}

Berdasarkan Tabel. 1 diperoleh parameter kualitas perairan laut Kota Dumai dari ketiga titik stasiun penelitian ditemukan nilai rata-rata suhu berkisar antara $30,3-31,3^{\circ} \mathrm{C}$, nilai rata-rata salinitas yang diukur pada ketiga stasiun adalah 25 ppt, sedangkan nilai rata-rata kecepatan arus pada setiap stasiun adalah 0,13-0,14 $\mathrm{m} /$ det.

Suhu yang tinggi menyebabkan proses fragmentasi plastik menjadi partikelpartikel kecil. Hal ini sesuai dengan pernyataan Hastuti (2014) yang menyatakan bahwa air laut mampu menyerap dan menyebarkan sinar UV sehingga plastik yang berada pada permukaan air laut akan lebih mudah mengalami fragmentasi.

Rata-rata salinitas di periaran laut Kota Dumai bernilai rendah. Rendahnya salinitas pada penelitian ini karenakan pengukuran kualitas perairan berada tidak jauh dari daerah garis pantai dan muara sungai. Dahuri et al., (2001) menjelaskan secara umum salinitas di permukaan perairan Laut Indonesia berkisar antara 3234\%o. Dalam putusan mentri Lingkungan Hidup No.51 Tahun 2004 menjelaskan salinitas untuk biota laut berkisar 33-34 \% . Dari penelitian ini daerah yang dekat dengan pantai dan muara sungai nilai salinitasnya dibawah baku mutu. Hal ini di sebabkan oleh masuknya air tawar ke dalam air laut yang menyebabkan rendahnya salinitas.

Teuten et al., (2009) menyatakan bahwa tingkat plastik terfragmentasi di dalam air laut bergantung pada densitas plastik. Daya apung yang tinggi dapat membuat plastik berdensitas rendah mudah mengapung dan terpapar sinar matahari sehingga fragmentasi semakin cepat. Kecepatan arus di perairan laut Kota Dumai sangat lemah dan lambat. Hal ini salah satu penyebab jumlah mikroplastik yang tersebar di perairan laut Kota Dumai memiliki jumlah yang relatif sama. Pergerakan arus merupakan salah satu faktor utama dalam penyebaran partikel mikroplastik di perairan laut. Menurut Coppock et al., (2017) rendahnya kecepatan arus menyebabkan pergerakan dari parikel mikroplastik tersebut menjadi lambat dan mengalami penumpukan sehingga diduga kuat proses fragmentasi plastik hanya terjadi di dearah tersebut. 
Jenis dan Kelimpahan Miroplastik pada Air Laut

Hasil pengamatan kelimpahan mikroplastik pada sampel air laut di setiap titik stasiun diperoleh nilai kelimpahan lebih kecil. Hasil penelitian ini berbeda dengan penelitian yang dilakukan oleh beberapa peneliti dengan lokasi yang berbeda. Perbadingan kelimpahan disajikan pada Tabel 2.

Tabel 2. Perbandingan partikel mikroplastik pada perairan yang berbeda

\begin{tabular}{lll}
\hline Lokasi & Jumlah $\left(\right.$ partikel $\left./ \mathrm{m}^{3}\right)$ & Sumber \\
\hline Teluk Jakarta & $2881-7472$ & Manalu (2017) \\
Selat Bali & 1633,33 & Siagian (2018) \\
eoje Island & 3353 & Song et al., (2013) \\
Black Sea Waters & $600-1200$ & Aytan et al., (2016) \\
Perairan Laut Dumai & $333,3333-456,6667$ & Penelitian ini (2019) \\
\hline
\end{tabular}

Berdasarkan Tabel 2, kelimpahan partikel mikroplastik yang diperoleh pada perairan Kota Dumai lebih kecil dibandingkan dengan 4 lokasi penelitian lainnya. Perbedaan kelimpahan dari setiap penelitian disebabkan oleh adanya perbedaan karakteristik lokasi penelitian. lokasi penelitian ini merupakan daerah pesisir yang dipengaruhi oleh aktivitas antropogenik seperti pemukiman, industri, wisata pantai, pertanian, dan perikanan.

Lokasi penelitian dibagi atas 3 titik stasiun dengan karakteristik yang berbeda. Stasiun 1 merupakan daerah yang dekat dengan muara sungai masjid dan perindustrian, diduga bahwa distribusi sampah berasal dari aliran sungai dan masuk ke laut. Stasiun 2 merupakan daerah pantai wisata, diduga distribusi sampah berasal dari sisa pembuangan dari wisatawan. Stasiun 3 merupakan kawasan pelabuhan pendaratan ikan (TPI) kawasan ini merupakan daerah dengan aktivitas antropogenik yang ramai dan merupakan kawasan yang berdekatan dengan Pusat Kota Dumai, dimana distribusi sampah plastik sisa pembuangan dari kapal-kapal nelayan

Hasil penelitian menunjukkan kelimpahan mikroplastik yang diperoleh dari sampel air laut dari 3 titik stasiun berbeda dapat dan diamati pada Gambar 1 .

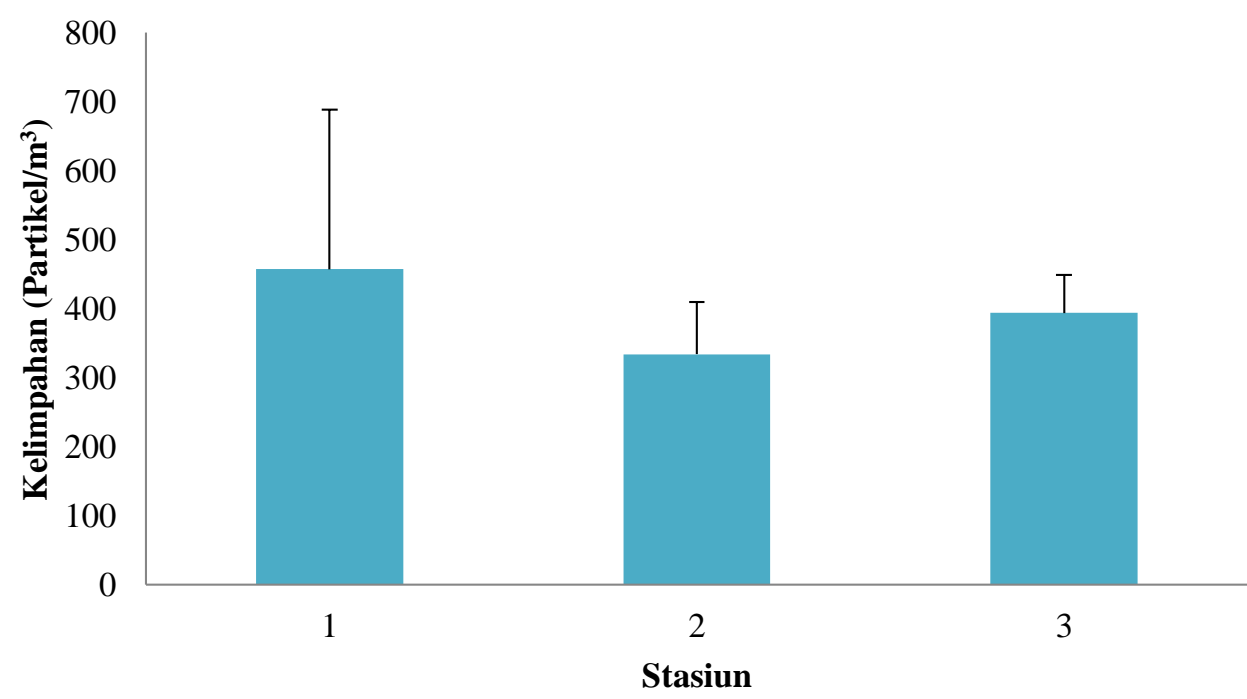

Gambar 1. Kelimpahan mikroplastik antar stasiun 
Diketahui bahwa, nilai rata-rata kelimpahan mikroplastik setiap stasiun yang diamati menunjukkan stasiun 1 memiliki kelimpahan mikroplastik tertinggi, diperoleh nilai rata-rata kelimpahan yaitu 456,6667 partikel $/ \mathrm{m}^{3}$ dan kelimpahan terendah pada stasiun 2 yang memiliki nilai rata-rata kelimpahan yaitu 333,3333 partikel $/ \mathrm{m}^{3}$. Berdasarkan hasil pengujian ANOVA One-way menunjukkan bahwa nilai Sig $(0,603)>0,05$. Hal ini menyatakan bahwa jumlah mikroplastik antar stasiun tidak berbeda nyata.

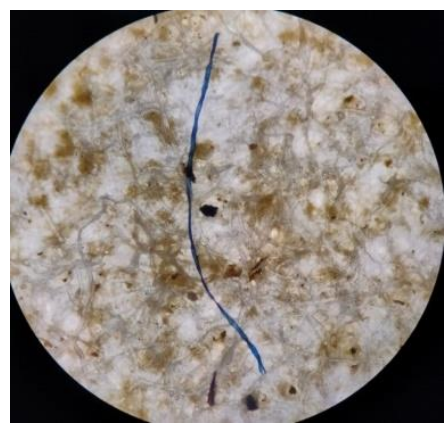

a

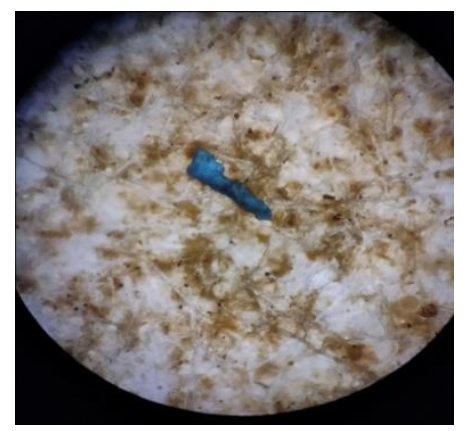

b
Hasil penelitian ini ditemukan 3 jenis mikroplastik yang terdapat pada sampel air laut perairan Kota Dumai yaitu fiber, fragmen, dan film . Diketahui bahwa mikroplastik berjenis fiber merupakan miroplastik dengan nilai rata-rata kelimpahan paling tinggi sedangkan mikroplastik berjenis fragmen merupakan mikroplastik dengan nilai rata-rata kelimpahan paling rendah. Jenis dan kelimpahan mikroplastik yang ditemukan dapat dilihat pada Gambar 2 dan Gambar 3.

Gambar 2. Jenis mikroplastik yang ditemukan pada sampel air laut dengan tipe fiber (a), fragmen (b), film (c)

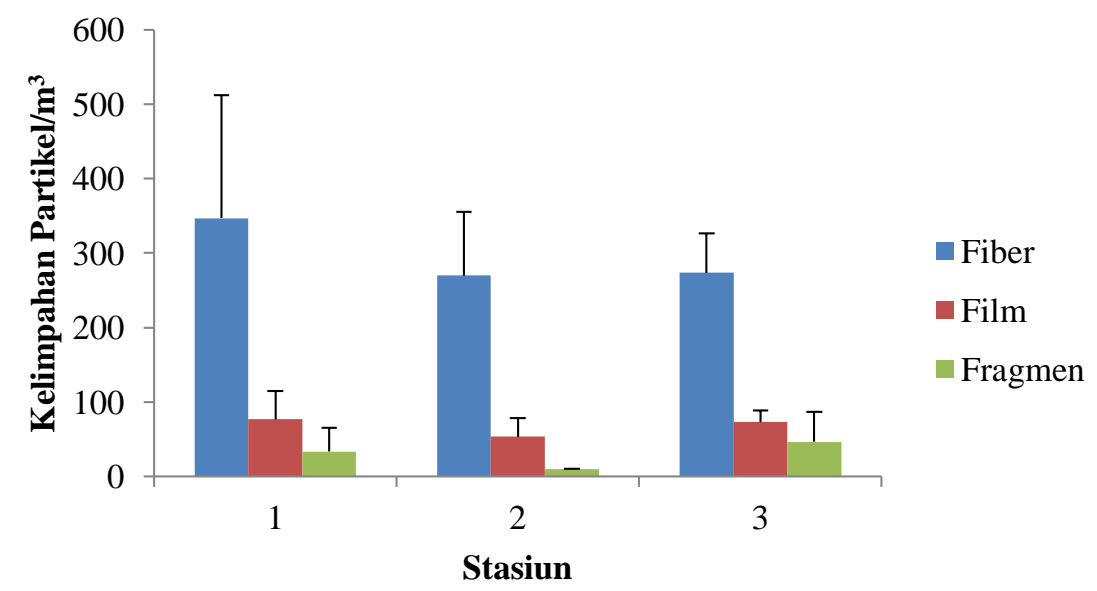

Gambar 3. Rata-rata kelimpahan mikroplastik antar stasiun berdasarkan jenis mikroplastik sampel air laut

Berdasarkan Gambar 3, mikroplastik berjenis fiber merupakan mikroplastik yang paling dominan ditemukan dibandingkan fragmen dan film. Rata-rata kelimpahan mikroplastik jenis fiber pada stasiun $1>$ stasiun $3>$ stasiun 2 , selanjutnya fragmen pada stasiun $3>\operatorname{stasiun~} 1>\operatorname{stasiun} 2$, selanjutnya pada film stasiun $1>$ stasiun 3 $>$ stasiun 2 . 
Menurut Barnes et al., (2009), kepadatan sampah plastik berkorelasi kuat dengan jumlah manusia di suatu wilayah. Plastik yang dihasilkan oleh aktivitas manusia di sekitar perairan akan menumpuk dalam waktu yang cukup lama disebabkan kecepatan aliran sungai di lokasi penelitian hanya mencapai $0,13-0,14$ $\mathrm{m} / \mathrm{s}$ yang memungkinkan untuk mengalami fragmentasi menjadi ukuran yang lebih kecil. Kelimpahan mikroplastik ini dapat meningkat apabila semakin banyak plastik yang masuk dan menumpuk di perairan.

Pada penelitian ini hanya ditemukan tiga jenis mikroplastik yaitu jenis mikroplastik fiber, fragmen, dan film, sedangkan jenis mikroplastik seperti pelet tidak ditemukan pada penelitian ini. Tiga jenis mikroplastik yaitu fiber, film, dan fragmen berasal dari sumber mikroplastik sekunder. Sumber mikroplastik sekunder meliputi serat atau potongan hasil pemutusan rantai dari plastik lebih besar yang mungkin terjadi sebelum mikroplastik memasuki perairan. Potongan mikroplastik dapat berasal dari jala ikan, alat rumah tangga, kantong plastik yang memang dirancang untuk terdegradasi di lingkungan. Sumber mikroplastik sekunder memiliki waktu tinggal yang relatif lebih lama di wilayah perairan, baik di perairan alami maupun buatan. Sumber mikroplastik sekunder di yakni menjadi sumber utama mikroplastik dalam lingkungan perairan (Victoria, 2017).

Jenis mikroplastik yang dominan dalam penelitian ini adalah jenis mikroplastik fiber dengan nilai kelimpahan tertinggi pada setiap stasiunnya, sedangkan mikroplastik berjenis fragmen dan film merupakan yang paling sedikit ditemukan di setiap stasiunnya. Hasil ini menunjukkan adanya kesamaan dari penelitian yang dilakukan oleh (Boerger et al., (2010); Lusher et al., (2013); Neves et al., (2015) dengan jenis mikroplastik yang dominan yaitu fiber.
Mikroplastik berjenis fiber merupakan mikroplastik yang berasal dari fragmentasi monofilament (serat tunggal) dari jaring ikan, tali (Nor dan Obbard, 2014).

Fragmen memiliki nilai kelimpahan terendah dalam penelitian ini. Fragmen merupakan pecahan dari plastik yang tebal, kaku dan memiliki bentuk tidak beraturan (Kovač Viršek et al., 2016). Pada penelitian ini fragmen diduga masuk kedalam perairan melalui aktivitas manusia yang berada disekitar lokasi sampling (muara sungai masjid, muara sungai dumai, dan pantai wisata) seperti pecahan plastik, ember, alat-alat besar lainnya berbahan dasar plastik yang digunakan untuk keperluan nelayan mencari ikan.

Film ditemukan dengan nilai persentase tertinggi kedua dalam penelitian. Film memiliki densitas lebih rendah dibandingkan jenis mikroplastik lainnya sehingga lebih mudah ditranportasikan dalam air (Hastuti, 2014). Film sama halnya seperti fragmen berasal dari pecahan plastik yang lebih besar hanya saja berbentuk tipis, lentur dan pada umumnya transparan (Kovač Viršek et al., 2016). Film berasal dari botol plastik air mineral, plastik wrap, plastik kemasan dan sebagainya.

Berbeda dengan hasil penelitian yang dilakukan oleh Manalu (2017) Teluk Jakarta dan Siagian (2018) Perairan Selatan Selat Bali dengan jenis mikroplastik yang paling dominan ialah jenis mikroplastik fragmen. Penelitian yang dilakukan Eriksen et al., (2013) di perairan danau Laurentian Great (air tawar), memaparkan hasil kelimpahan mikroplastik berdasarkan jenis mikroplastik yang paling dominan yaitu fragmen, meskipun Eriksen et al., (2013) melakukan penelitian pada danau, tetapi kondisi ini dapat menggambarkan perairan yang berbatasan langsung dengan lokasi yang tingkat kepadatan penduduk yang sangat tinggi. 
Jenis dan Kelimpahan Mikroplastik Pada Ikan Senangin

Selain ditemukan pada air laut, partikel mikroplastik juga terdapat pada organ pencernaan ikan senangin ( $E$. tetradactylum). Hasil pengamatan kelimpahan miroplastik pada organ pencernaan ikan senangin $(E$. tetradactylum) diperoleh nilai rata-rata 933,3333-1933,3333 partikel/ind. Hasil yang ditemukan lebih besar dari pada hasil beberapa penelitian yang dilakukan pada beberapa biota berbeda. Perbandingan kelimpahan disajikan pada Tabel 3.

Tabel 3. Perbandingan kelimpahan mikroplastik pada biota dan perairan yang berbeda

\begin{tabular}{llll}
\hline Lokasi & Biota & $\begin{array}{l}\text { Kelimpahan } \\
\text { (partikel/ind) }\end{array}$ & Sumber \\
\hline $\begin{array}{llll}\text { Perairan Kota Dumai } \\
\text { Perairan Pulau Karimun }\end{array}$ & Ikan Seangin & $933,3333-1933,3333$ & Penilitian ini (2019) \\
$\begin{array}{l}\text { Besar } \\
\text { Selat Bali }\end{array}$ & Ikan Lemuru & $2-13$ & Rukimin (2019) \\
$\begin{array}{l}\text { Kepulauan Spermonde, } \\
\text { Sulawesi Selatan }\end{array}$ & Kerang & $2-3$ & Yudhantari (2019) \\
\hline
\end{tabular}

Untuk perbadingan kelimpahan setiap sampel ikan senangin (E. tetradactylum) dapat dilihat pada Gambar 2 yang diketahui bahwa kelimpahan mikroplastik yang ditemukan pada sampel ikan senangin $(E$. tetradactylum) menunjukkan nilai kelimpahan tertinggi, pada sampel berlabel ikan 1 dengan nilai kelimpahan 1933,3333 partikel/ind, sedangkan nilai kelimpahan terendah pada sampel berlabel ikan 5 dengan nilai kelimpahan 966,6666 partikel/ind. Hasil pengujian ANOVA One way pada setiap sampel ikan senangin $(E$. tetradactylum) diperoleh nilai Sig $(0,451)>$ 0,05 . Hal ini menunjukkan bahwa setiap sampel tidak berbeda nyata.

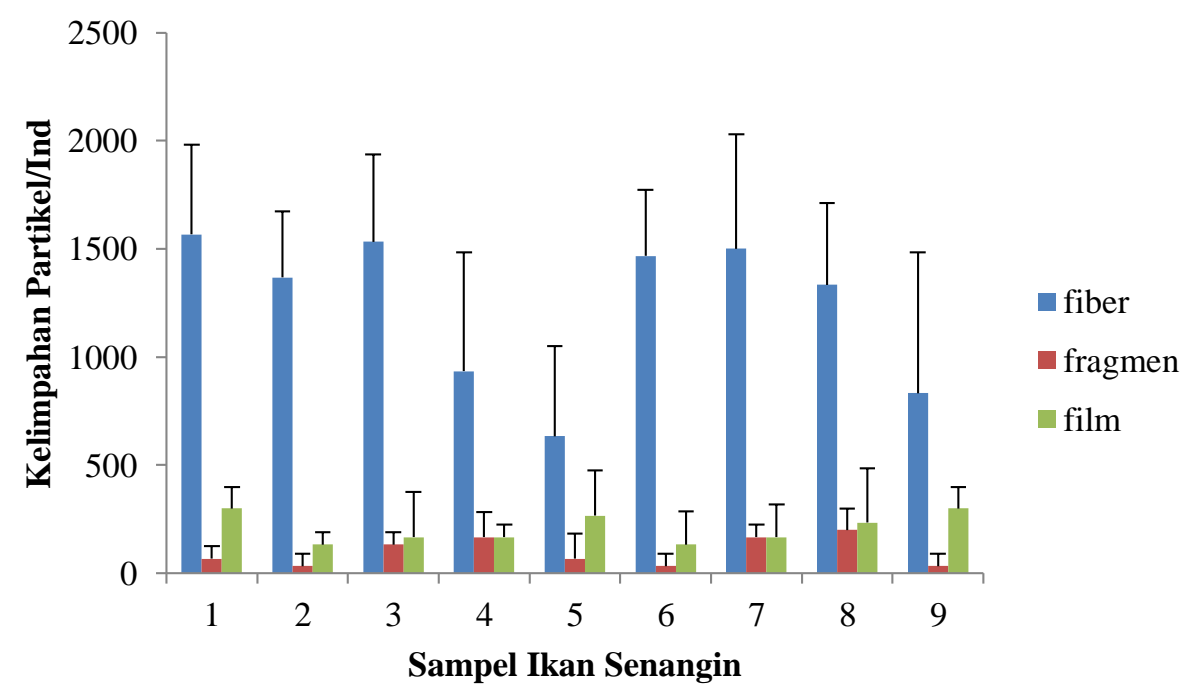

Gambar 4. Kelimpahan jenis mikroplastik sampel ikan senangin

Berdasarkan Gambar 4, mikroplastik berjenis fiber merupakan mikroplastik yang paling dominan dibandingkan dengan mikroplastik berjenis fragmen dan film.
Kelimpahan jenis mikroplastik fiber tertinggi, ditemukan pada sampel ikan 1 dan yang terendah pada sampel ikan 5 . Selanjutnya kelimpahan jenis mikroplastik 
fragmen tertinggi terdapat pada sampel Ikan 8, dan terendah pada ikan 2, ikan 6, dan ikan 9. Sedangkan kelimpahan jenis mikroplastik film tertinggi pada sampel ikan 1 dan ikan 2, terendah pada ikan 2 dan ikan 6.

Perbedaan kelimpahan mikroplastik masing-masing penelitian disebabkan oleh karakteristik lokasi penelitian yang menerima limbah antropogenik yang berbeda, dan objek penelitian yang memiliki sifat makan feeding habit yang berbeda pula (Manalu,2017). Menurut Motomura (2004), ikan Senangin pada umumnya memakan krustasea kecil dan ikan berururan kecil, sedangkan ikan lemuru merupakan ikan pemakan jasad planktonik (Planktonivore), sedangkan teripang dan kerang merupakan biota pemakan endapan/sedimen deposit feeder (Darsono, 2003).

Jenis mikroplastik yang dominan di temukan pada organ pencernaan ikan senangin (E. tetradactylum) adalah jenis mikroplastik fiber, film, fragmen. Mikroplastik fiber merupakan yang paling tinggi, ini sesuai dengan penelitian yang dilakukan oleh Lusher et al., (2013) yang melaporkan bahwa jenis mikroplastik fiber yang tertinggi pada saluran pencernaan ikan adalah fiber $(68,3 \%)$. Nor dan Obbard (2014) berpendapat bahwa mikroplastik jenis fiber berasal dari degradasi berbagai aktivitas nelayan baik itu alat tangkap maupun dari tali kapal yang terurai masuk keperairan dan terakumulasi dalam tubuh biota.

Menurut Reiney (2018) puntung rokok yang merupakan serat sintetis, adalah bahan pencemar terbesar di laut dunia. Diduga aktivitas antropogenik sepertinya adanya pengaruh bahan-bahan pakaian, puntung rokok, tali-temali, dari aktivitas penangkapan ikan di perairan.

Mikroplastik jenis film adalah mikroplastik yang tertinggi kedua yang ditemukan dalam organ pencernaan ikan senangin. Mikroplastik ini diduga masuk kedalam organ pencernaan ikan senangin melalui hasil pembuangan limbah plastik berdensitas rendah yang berasal dari pembuangan limbah rumah tangga, wisatawan, dan aktivitas antropogenik lainnya. Sifat mikroplastik film yang berasal dari sampah plastik berdensitas rendah, memungkinkan terbawa arus hingga masuk ke perairan. Menurut Kingfisher (2011) mikroplastik jenis film merupakan polimer plastik sekunder yang berasal dari fragmentasi kantong plastik atau plastik kemasan yang memiliki densitas rendah.

Mikroplastik yang paling sedikit ditemukan dalam penelitian ini ialah jenis fragmen. Menurut Browne et al., (2011) dan Dewi et al., (2015) menyatakan bahwa mikroplastik jenis fragmen bersumber dari degradasi pecahan-pecahan plastik yang besar. Botol minuman, sisa-sisa toples yang terbuang, kemasan makanan cepat saji dan buangan sampah perkantoran sehingga diduga mikroplastik jenis fragmen berasal dari aktifitas antropogenik yang bersal dari sungai dan pantai wisata menjadi sumbersumber pencemaran jenis tersebut.

\section{KESIMPULAN DAN SARAN}

Dari hasil penelitian ini dapat disimpulkan bahwa jenis mikroplastik yang ditemukan pada air laut dan ikan senangin (E. tetradactylum) yaitu jenis mikroplastik fiber, fragmen, dan film. Mikroplastik berjenis pelet tidak ditemukan pada penelitian ini. Kelimpahan mikroplastik pada sampel air laut berkisar antara 333,3333-456,6667 partikel/m3, sedangkan kelimpahan mikroplastik pada ikan senangin ( $E$. tetradactylum) adalah 966,6667-1933,3333 partikel/ind.

Penelitian selanjutnya sebainya dilakukan pada biota di dasar perairan dan sedimen sehingga dapat mengetahui pengaruh fluktasi pergerakan air laut terhadap jumlah mikroplastik pada sedimen dan organisme. 


\section{DAFTAR PUSTAKA}

1. Victoria, V.A. (2017). Kontaminasi Mikroplastik di Perairan Tawar. Teknik Kimia. IPB Press.

2. Moore, C.J. (2008). Synthetic polymers in the marine environment : A rapidly increasing, 108, 131-139.

3. Tankovic, M.S., S. Perusco, V.J. Godrijan, D. and M. Pfannkuchen. (2015). Marine Plastic Debris in the Northeastern Adriatic. Procceedings of the MICRO 2015 Seminar of Microplastic Issues. Micro 2015: Book of abstracts.

4. Hidalgo-Ruz, V., L. Gutow, R.C. Thompson, M. Thiel. (2012). Microplastics in the marine environment: a review of the methods used for identification and quantification. Environmental Science and Technology, 46:3060- 3075.

5. Li, J., X. Qu., L. Su., W. Zhang, D. Yang, P. Kolandhasamy, D. Li, and H. Shi. (2016). Microplastics in mussels along the coastal waters of China. Environmental Pollution, 214: $177-184$.

6. Hastuti, A.R. (2014). Distribusi Spasial sampah laut di ekosistem mangrove Pantai Indah Kapuk Jakarta. Tesis. Departemen Manajemen Sumber Daya Perairan Fakultas Perikanan dan Ilmu Kelautan Institut Pertanian Bogor. 29 hal.

7. National Oceanic and Atmospheric Administration. (2013). Programmatic environmental assessment (PEA) for the NOAA Marine Debris Program (MDP). Maryland (US): NOAA. 168p.

8. BPS Kota Dumai. (2019). Dumai Dalam Angka 2019. Badan Pusat Statistik. Kota Dumai. 165 Hal

9. Dahuri,R., J. Rais, S. P. Ginting dan M.J. Sitepu. (2001). Penggolaan Sumber Daya Wilayah Pesisir dan Lautan Secara Terpadu. Penerbit Pradnya Paramita. Jakarta.

10. Teuten, L.E., Rowland, J.S., Galloway, S.T., Thompson, C.R., (2007). Potential for Plastics to Transport Hydrophobic Contaminants. Env. Sci Technol 41, 7759-7764.

11. Coppock, R.L., M. Cole, P.K.Lindeque, A.M.Queiros dan T.S.Galoway. (2017). A Small-Scale, Portable Method For Extracting Micropalstics From Marine Sediments. Journal Enviroment Pollution. 230: 829-837

12. Barnes DKA, Galgani F, Thompson RC, Barlaz M. (2009). Accumulation and fragmentation of plastic debris in global environments. Philos. Trans. R. Soc. London, B. 364: 1985-1998.

13. Boerger, M. C., L. G. Lattin, L. S. Moore, and J.C. Moore. (2010). Plastic ingestion by planktivorous fishes in the North Pacific Central Gyre. Elsevier. 60, 22752278.

14. Nor, N.H.M. dan J.P. Obbard. (2014). Micropalstic In Singapore's Coastal Mangrove Ecosystem. Marine Pollution Bulletin. 79: 278-283

15. Kovač, V. M., Palatinus, A., Koren, Š., Peterlin, M., Horvat, P., Kržan, A. (2016). Protocol for Microplastics Sampling on the Sea Surface and Sample Analysis. Journal Visual Exp 118: 1-9.

16. Eriksen,M., Mason, S., Wilson S, Box C, Zellers A, Edwards W, Farley H, Amato S. (2013). Microplastic pollution in the surface waters of the Laurentian great lakes. Mar. Pollut. Bull. 77 (1): 177-182. 
17. Manalu, A. A. (2017). Kelimpahan Mikropalstik di Teluk Jakarta. Tesis. Sekolah Pascasarjana. Institut Pertanian Bogor. Bogor

18. Motomura H. (2004). Threadfins of the world (Family Polynemidae): An annotated and illustrated catalogue of Polynemid species known to date. FAO Species Catalogue for Fishery Purpose. 3: $117 \mathrm{p}$

19. Darsono, P. (2003). Sumber Teripang dan Pengelolaannya. Jurnal Oseana. 29(2):1-9.

20. Rukim, M. (2019). Identifikasi dan Distribusi Mikroplastik Pada Teripang (Paracaudina sp) Di Perairan Pulau Karimun Besar Provinsi Kepulauan Riau. Skripsi. Pekanbaru. Fakultas Perikanan dan Kelautan. Universitas Riau.

21. Lusher, A.L., McHugh M, Thompson RC. (2013). Occurrence of microplastics in the gastrointestinal tract of pelagic and demersal fish from the English Channel. Mar. Pollut. Bull. 67 (1): 94-99.

22. Reiney, J. (2018). Plastic straw ban? Cigarette butts are the single greatest source of ocean trash. http://www.nbcnews.com/news/us-news/plastic-straw-ban-cigarette-buttsare-the-single-greatest-source-ocean-n903661[Diakses pada 4 Maret 2019].

23. Yudhantari, C. I. A. S., I. G. Hendrawan., N. L. P. R. Puspitha. (2019). Kandungan Mikroplastik Pada Saluran Pencernaan Ikan Lemuru Protolan (Sardinella lemuru) Hasil Tangkapan Di Selat Bali. JMRT. 2(2):48-52

24. Sari, K. (2018). Keberadaan Mikroplastik Pada Hewan Filter Feeder Di Padang Lamun Kepulauan Spermonde Kota Makasar.Skripsi. Makasar. Program Studi Ilmu Kelautan Fakultas Ilmu Kelautan dan Perikanan. Universitas Hasanuddin.

25. Siagian, B.D.M. (2018). Analisis Perbandingan Kandungan Mikroplastik Menggunakan Metode Sampling Plankton Net dan Manta Net di Perairan Selat Bali. Skripsi. Universitas Brawijaya, Malang.

26. Neves, D., P. Sobral, J.L. Ferreira, \& T. Pereira. (2015). Ingestion of microplastics by commercial fish off the Portuguese coast. Marine Pollution Bulletin, 101: 119-126.

27. Kingfisher, J. (2011). Micro-plastic Debris Accumulation on Puget Sound Beaches. Washington: Port Townsend Marine Science Center. http://www.ptmsc.org/Science/plastic_project/Summit\%20Final\%20Draft pdf. Di unduh pada tanggal 27 November 2019

28. Browne, A.M., P. Crump, J.S. Niven, E. Teuten, A. Tonkin, T. Galloway, R. Thompson. (2011). Accumulation of Microplastic on Shorelines Woldwide: Sources and Sinks. Environmental Science Technology. 45, 9175-9179.

29. Dewi, I. S., Anugrah, A. B., Irwan, R. R. (2015). Distribusi mikroplastik pada sedimen di Muara Badak, Kabupaten Kutai Kartanegara. Depik 4 (3): 121-131. 